\title{
Crossing the Ethic - Non Ethic Border: A Cognitive Dissonance Theory Approach
}

\author{
Silvia López Paláu*, Beatriz Rivera-Cruz \\ University of Puerto Rico, Rio Piedras Campus, Puerto Rico \\ *Corresponding author: slopez@coqui.net \\ Received January 17, 2014; Revised February 18, 2014; Accepted March 03, 2014
}

\begin{abstract}
The main purpose of this study is to identify the importance of several variables in the ethical decision making process, propose a model that incorporates the Festinger (1957) Cognitive Dissonance Theory and the Jones (1991) model. With that in mind a measurement instrument was developed using the Personal Ethical Threshold (Comer and Vega, 2008). The results provide valuable data worth considering in the design of business curriculums.
\end{abstract}

Keywords: ethics, cognitive dissonance, decision making models, gender

Cite This Article: Silvia López Paláu, and Beatriz Rivera-Cruz, "Crossing the Ethic - Non Ethic Border: A Cognitive Dissonance Theory Approach.” American Journal of Educational Research, vol. 2, no. 3 (2014): 123134. doi: 10.12691/education-2-3-2.

\section{Introduction}

Ethics researchers have faced two key challenges. First, the need to develop theory to ground research. Second, the urgency to develop quantitative approaches validated by researchers in the quantitative paradigm (Bay 2002). Despite the considerable effort researchers has been devoted to ethics studies in the business arena, a theory capable to reasonably explain and/or predict ethical behavior is still needed.

Most researches attempt to explain the ethical - non ethical behavior using Kohlberg's Moral Development Theory (1976) and the Defining Issues Test (DIT) developed by Rest (1979). The former provides a theoretical framework, and the latter provides a quantitative measure that may be used in further analysis. Great supporting and contradictory evidence has been accumulated for the theory. Bay (2002, 160) identified three issues related to the DIT, calling into question its use in ethics research:

(1) divergence between the theory and the DIT exists.

(2) potential biases when the instrument is used

(3) there is no clear relationship between the DIT and behavior.

In addition to the methodological concerns, other authors (Marnburg, 2001 and Reiter 1996, among others) criticize the approach at the theoretical level. Gilligan's (1982) critique is the most noticeable. She proposes the Care Theory as an alternative approach. However, the most important issue in the controversy is that the results of empirical research consistently show the failure of Kohlberg's theory to explain or predict the behavior under study.

Other approaches have focused on the ethics of individuals or other personal, organizational or cultural variables, mainly from a theoretical perspective and minimally from a quantitative, or empirical approach (for example, Trevino 1986; Bommer et al. 1987; Ferrell and Gresham, 1985; López Palau 2000, 2001; Lopez Palau and Rivera cross 2007; Rivera Cross and López Palau 2008). Proposed ethical decision-making process models have identified several influential factors. Culture has been one of environmental factors most quoted and discussed in the literature (Becker and Fritzsche 1987; Honeycutt et al. 1995; Teoh et al. 1999; Smith and Hume 2001, 2005; López Palau 2006, 2008; McGee and López Palau 2008, among others). Together, these studies reveal that culture affects the way in which individuals identify, understand and face ethical conflicts. This makes it necessary to take into account the cultural context in studies on the subject.

Gender is one of the most studied personal variables (Luthar et al., 2005; Gump et al, 2000; Loe et.al. 2000; Roxas et. Al., 2004; Cohen et al. 1998; McGee et. Al., 2007; Patterson 1994). Empirical evidence at the moment is contradictory. Recent studies suggest that gender may be an influential factor at some stages of the decisionmaking process, but not in others.

Another important set of variables relate to the characteristics of the situation and their effect on the decision-making process (Jones, 1991; Davis et al., 1998; Tsaliskis, et al., 2008; Barnett and Valentine, 2004; Chia and Mee, 2000; May and Pauli, 2002, McMahon and Harvey, 2006; Vittel et., 2008; Frey, 2000; Shinghapakdi et al., 1994, 1996,1999). Studies suggest that the characteristics and specific circumstances of the situation influence the behavior of individuals.

In summary, various models exist that explain the ethical behavior of individuals. The models proposed present the phenomenon of ethical decision-making as a multidimensional, but linear and unidirectional process. Two important variables have been consistently identified: the cultural context and the situation. Gender could 
influence some stages of the decision-making process. However, the empirical evidence still continues to show examples of good people acting badly, without a reasonable answer to this problem.

\subsection{Objectives}

There is a need to develop theoretical models to explain and predict ethical/non ethical individual behavior and to create reliable measurement instruments for that purpose that take the cultural context into consideration. With that in mind, the main purpose of this study is to identify the importance of several variables in the decision-making process, using the Cognitive Dissonance Theory proposed by Festinger (1957), and the Jones (1991) model as the conceptual framework. The data gathering instrument is based on the Personal Ethical Threshold (PET) developed by Comer and Vega (2008).

Specific objectives are: (1) to identify situational pressures affecting the intention to act ethically among participants; (2) to determine the factors that affect the evaluation of an action and the probability to execute it (3) to examine possible gender differences.

\subsection{Importance of the Study}

This study is important from a theoretical and practical perspective. It proposes a dynamic and bidirectional model that for the first time considers the experience accumulated by the individual and its influence on subsequent decisions. The proposed model offers several advantages over existing decision-making models. First, the components are similar to those proposed in previous models, but include a new conceptualization of the relationships among them, while integrating the theory of cognitive dissonance. Second, presents the decisionmaking as a concatenated process, rather than linear, in which the previous experiences influence subsequent decisions. Third, demonstrates the influence of gender, specifically, in relation to the intention to act, but not at the evaluation stage. In practical terms, the study develops a reliable instrument capable of measuring an index that captures the individuals' likeliness to act unethically and the relative importance of various factors that can influence such index.

The results obtained in this study have important practical implications. Examples include contributing a new approach to the design of programs for training in ethics at higher education institutions, businesses and government agencies. It raises the importance of developing and strengthening the ability of students (future accountants, managers and professionals) to deal with the pressures of the environment from a practical and realistic perspective that enables them to live and act in agreement with their values and beliefs. This study identifies the need to develop new methodologies, content, and approaches to teach ethics and to integrate the topic to new educational models for educating business students.

\subsection{Literature Review}

Studies conducted during the 80's suggest models to guide the ethical decision-making, through a variety of structures and variables (Rest 1986; Trevino 1986; Brommer et al. 1987; Ferrell and Gresham, 1985; Ferrell,
Gresham, and Fraedrich, 1989; Hunt and Vitell, 1986; Dubinsky and Loken, 1989 and 1991 Jones, among others). The simplest model was proposed by Rest (1986). It consists of four steps: (1) recognition of the ethical dilemma; (2) moral judgment (3) intentions to act and (4) behavior. In the first step the individual recognizes that there is an ethical dilemma. In the second step the individual uses a range of strategies to distinguish among ethical and unethical choices. In the third step, the individual decides how he or she will act. This step is based on the theory of reasoned behavior developed in social psychology by Ajzen and Fishbein (1980) and Fishbein and Ajzen (1975). According to this theory, actual behavior is highly correlated with the intention to act in such a way that it can be reasonably predicted by just the intention to act, according to certain conditions as established by theory. In the last step, the individual performs the selected alternative.

Jones (1991) proposed the moral intensity of the dilemma as a key variable in the decision making process, affecting each of the steps proposed by Rest (1986). Moral intensity is defined as the characteristics of the dilemma that force the individual to use moral reasoning. According to Jones, the moral intensity of a dilemma is composed by six elements: (1) the magnitude of the consequences; (2) the probability of the effect; (3) social consensus; (4) temporal immediacy; (5) proximity and (6) a concentration effect. The magnitude of the consequences refers to the amount of damage or benefit an alternative action may cause, increasing the moral intensity as potential damages increase. The probability of the effect refers to the likelihood of the action occurring and causing damage, in this case, the higher the moral intensity the higher the probability of occurrence and actual damage is. Social consensus refers to the degree of social agreement on the moral of the action; the higher the understanding about the immorality of the act, the more moral intensity generated. The temporal immediacy refers to the amount of time between the occurrence of the action and its consequences, the shorter the period, the higher the moral intensity. The proximity refers to the physical, psychological, cultural or social proximity of the actor to the victim or beneficiary, the closer the relationship, the higher the moral intensity. Finally, the concentration effect refers to the proportion of the damage or benefit in relation to the number of people affected, the moral intensity increases with the increase in the portion of damage that affected every individual. Jones (1991) proposes that problems with a greater moral intensity (1) will be recognized as ethical dilemmas, (2) will require a more sophisticated moral reasoning, (3) will result in moral intent, and, (4) will show a moral result, more frequently than less moral intensity situations.

Various studies have examined the Jones (1991) model with mixed results in regards to the factor structure of moral intensity and its effect on the different steps previously described (Alleyne et., 2006; Carlson et al, 2002; Coralm et al, 2008; Kelley, 2003; Singh, 2007; et Leitsch, 2004, 2006; Ng, 2009; et Nill, 2005; Paolillo et to 2002; Waiseeleski et al, 2008; Sweeney 2009 et). Results include one to six factors structures as established by Jones.. The results of the effect of each component of the moral intensity in the first three steps of the model range from significant relationships to no effect at all. In some 
studies the significance of the effect varies depending on the evaluated scenarios. It is important to take into account that methodological differences in studies may have caused part of the inconsistency in the results.

The model proposed by Jones provides a description of the decision-making process reasonably consistent with the daily reality we observe. However, it leaves out two important elements. First, it limits its definition of ethical conflict to those where the action of a person, of its own free will, could cause damage or benefits to others (Jones, 1991) without considering the beneficial or harmful effect to that person. McMahon and Harvey (2007) questioned if it is possible to make decisions of an ethical nature without considering the self as an interested party in the results. Second, the proposed model defines the process of decision-making as a linear process that ends with the implementation of an action without considering the effect of such action in the possible solution of future ethical dilemmas. What may cause that a moral low-intensity conflict becomes a high-intensity conflict, still needs an answer. This study proposes to incorporate the theory of the cognitive dissonance developed by Festinger (1957) to the Jones model of decision-making in an attempt to find an answer to the concerns previously presented.

The theory of cognitive dissonance belongs to the category of action-opinion theories which are somewhat contrary to intuition. The apparent contradiction is that it seems more logical that our actions are the result of our beliefs and attitudes and not its cause. This theory was developed by Festinger (1957) and the central idea is that in general, people prefer to have thoughts coherent with each other. Such knowledge can be an attitude, an emotion, behavior, a value, and so on. The theory has three main statements. First, humans are sensitive to inconsistencies between actions and beliefs. Second, when the person recognizes the inconsistency it leads to dissonance and will be motivated to solve it. The dissonance is defined as a state of unpleasant psychological tension. Third, the dissonance can be resolved in one of three ways: (1) by changing the belief, (2) by changing the behavior, or (3) changing the perception of the action.

The theory goes beyond the individuals' voluntary action and proposed several hypotheses about the concept of forced compliance. This occurs when a person decides to execute a behavior that he or she considers inappropriate. The situation becomes mandatory by the offer of any reward or the threat of punishment to remove the natural resistance of the person to such behavior. The three hypotheses are as follows: (1) the offer of reward or punishment to make another behave contrary to their beliefs almost always is going to cause dissonance ; (2) while most important is the belief, the greater the amount of reward or punishment required to get the behavior and the higher the dissonance generated; and (3) the maximum possible dissonance is created when the reward or punishment is just enough to get the opposite behavior.

The importance of ethics as a topic of instruction in management education is mainly due to the large scandals revealed by the media. The reported cases although dramatic and spectacular are not as frequent or common as one may think. However, every day, in common and ordinary circumstances many people face ethical conflicts and are forced to act against their beliefs. Moser (1988) argues that sexual harassment, discrimination, neglect, bribes and unfair competition, for example, are everyday situations that may not be reported but are noticed. In this environment, many people are likely to be "forced" to act against their beliefs, creating a state of dissonance. If the way to solve this dissonance is changing the perception of the action, then, collectively, we have a trivialization and desensitization process of the ethical conflicts. Therefore, apart from the moral intensity of the situation itself, it is important to examine how previous behaviors influence individuals' decision making process. Similarly, it is important to identify those rewards or punishments that could make a person to act against their principles.

Comer and Vega (2008) designed the Personal Ethical Threshold (PET) instrument to measure the susceptibility of individuals to situational pressures which may result in unethical behavior. They define the situational pressure as the positive consequences that an individual can achieve for crossing the ethical boundaries or negative consequences for not crossing them. The instrument measures such pressures in situations of differing moral intensities. While the reliability of the scale was quite low (.55) and the authors suggest review or deletion of four of the ten scenarios used, the novel approach used in the study should be regarded as a promising alternative. This study is intended to be a step forward.

Some researchers have invested considerable effort in analyzing gender differences. A meta analysis of 56 studies reports negligible or non-significant differences, due to gender (Thomas 1986). Another review in marketing Tsalikis and Fritzsche (1989) found that most studies concluded that women behave more ethically than men. In accounting and other disciplines, studies suggest that the judgment of women tend to be more ethical than those of men (Luthar et al., 2005; Loe et.al., 2000; Roxas et. Al., 2004; Cohen et al. 1998) while others have not found significant differences between women and men ethical decisions (McGee et. Al., 2007; Patterson 1994; López-Palau 2000, 2006). Few studies have concluded that men are more ethical than women. (Barnett \& Karson 1989; Weeks et. Al., 1999).

These apparently contradictory results may be due to the stage of the decision-making process that has been examined where some may be impacted by gender while others are not. Lopez-Palau (2006) found that men and women tend to make similar assessments, but sometimes express an intention to act differently. Consistent with the previous study, Valentine (2007) and Stedham et. al. (2007) found that gender appears to affect the intent towards the behavior, but not the assessment of the situation. These studies suggest that although men and women make the same ethical assessment as men do, men are more likely to act in an unethical manner than women. In summary, there are no conclusive results at present concerning the effect of gender or the direction of its impact.

\subsection{Theoretical Framework}

This study proposes a decision-making model incorporating the theory of cognitive dissonance into the model proposed by Jones, as illustrated in Figure 1. It focuses on the relationship between the steps of moral evaluation and the intention to act. In general, the model establishes that situational pressures influence both, the 
assessment of the situation and the intention to act in certain ways. Such influence has the effect of creating two types of interaction, that in which the assessment of the situation is affected by the intention of the individual, and this in turn is affected by the assessment of the situation. Further evaluations and the intention to act in a given situation affect future assessments and intentions in greater moral intensity scenarios. The model also proposes that individuals have general evaluation models for a diversity of actions as a result of their values and believes. When needed those general evaluations kick in as programmed. Gender of individuals is a moderator variable of the effect of situational pressures in the intention to act, but not in assessments of situations.

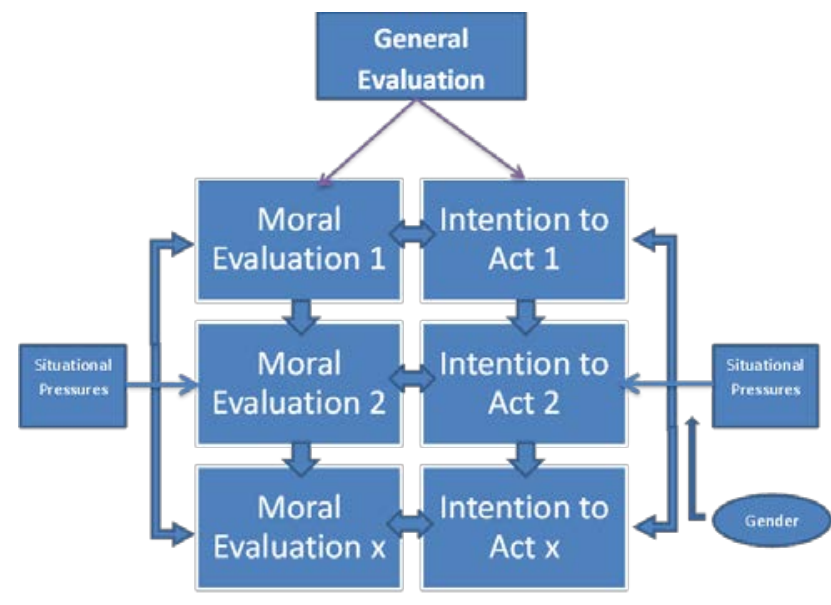

Figure 1. Decision Making Model Proposed

\subsection{Hypothesis}

On one hand, the Jones model proposes that the less ethical the assessment of a situation is, it is less likely that an individual will decide for an unethical behavior, the more intense the situation, the more frequent the relationship. On the other, the theory of cognitive dissonance establishes that when an action creates dissonance in the individual, one of the ways to resolve the conflict is performing a new evaluation consistent with the action. Considering both theories it could be argued that the decision making process of individuals is dynamic and can take either of the two directions and it is not a one-way linear process. Therefore, the existence of a correlation between moral evaluation and the intention to act supports both theories. The first proposed hypothesis is as follows.

$\mathrm{H}_{1}$ : The moral evaluation is correlated with the intention to act in a given situation.

Individuals create a scale of values and beliefs during their process of socialization and acculturation. This programming process starts within the family context, with experiences in school and through various social and cultural institutions where the person is creating general standards on what is good or evil beyond specific situations. Therefore, when people face an ethical conflict and must make a decision they use those general standards to perform the assessment of the particular situation so as to determine the intention to act in a particular manner. The following two hypotheses summarized the relationship of the general assessment with the ethical decision-making process.
$\mathrm{H}_{2}$ : The general evaluation is positively correlated with the specific evaluation of a specific situation.

$\mathrm{H}_{3}$ : The general evaluation is positively correlated with the intention to act in a given situation.

As experiences and situations grow more complicated, it is assumed that assessments made in less moral intensity situations will have an effect on assessments of situations of greater moral intensity. Thus the proposed model suggests that the assessment of a particular situation affects assessments of situations of greater moral intensity:

$\mathrm{H}_{4}$ : The evaluation of lower moral intensity situations is positively correlated with the evaluation of a situation of greater moral intensity.

According to the theory of cognitive dissonance a way for individuals to resolve the dissonance caused by an action is adjusting its assessment of the situation. The model proposed goes an additional step to propose that if an individual acts unethically in a particular situation, such behavior not only will affect its evaluation of the action, but their actions concerning situations of greater moral intensity, as stated in the following hypothesis:

$\mathrm{H}_{5}$ : The intention to act unethically is positively correlated with the intention to act unethically in situations of greater moral intensity.

Several studies suggest that the differences between men and women are more frequent in the intention to act than in the assessment of situations. One possible explanation is that men and women respond differently to situational pressures resulting in an intention to act differently, which is contained in the proposed model and in the following hypotheses.

$\mathrm{H}_{6}$ : Men are more willing to give in to pressures from the situation, making them more likely to have an unethical behavior than women.

$\mathrm{H}_{7}$ : Gender does not affect the evaluation of an ethical conflict.

\section{Methodology}

\subsection{Measurement Instrument}

The questionnaire consists of six sections. The first part requires participants to evaluate 15 statements relating to various forms of deception. A scale with opposite poles from $0 \%$ for Unethical to $100 \%$ for Ethical behavior was used. Four different scenarios are presented in which the actor deceive others in some way. In the first scenario, the actor lies to his teacher. In the second, the actor answers a test by a classmate. In the third, the actor includes false information in his resume for a job. In the last one, the actor includes false information in a document at work for the benefit of an employee.

The first two scenarios present student situations while the last two are related to work situations. The moral intensity of the described situations increases in each scenario as the consequences are more serious and affect more people (the concentration effect). In these questions, participants expressed the probability that they perform the described action under 20 different circumstances, each one implying different degrees of situational pressure. Pressures include considerations such like economic consequences, family issues, opportunity to perform, possibility of being caught, among others. These premises 
include many of the components of Jones' moral intensity model, and the consequences to the actor. A scale with opposite poles from $0 \%$ for $I$ will not do it to $100 \%$ for $I$ will do it was used. The last section consists of eight demographic questions.

\subsection{Statistics Tests}

An Evaluation Index was determined by calculating the response averages to the first question, related to various modes of deception stated in general terms. In addition, a Proclivity Index was calculated with the average of 20 statements in each question. Reliability tests were performed for the calculated indexes.

In addition, hierarchical regressions were made to determine the relationship between the evaluation of each situation and the proclivity to act, and the effect of the other variables. Whitney $U$ tests were performed to identify gender differences in responses. These tests were performed for each scenario and for the general evaluation and proclivity indexes.

\section{Results}

\subsection{Participants in the Sample}

The total sample consisted of 286 participants. Forty per cent of respondents are men. Nearly 90 percent of the sample is less than 25 years old. Eighty-five percent are undergraduate students and the remaining is studying master's degree. Fifty-seven percent considered themselves as middle class. Slightly less than half of the sample attend church regularly, mainly Catholic. Thirtyseven percent of participants approved a course in ethics, 33 percent had not taken an ethics class, and 30 percent was taking the course of business ethics at the time of the survey. About half of the sample are accounting students and the rest is distributed among the various specializations in business administration.

\subsection{Reliability}

Table 1. Averages y Confidence Coeficients

\begin{tabular}{|c|c|c|c|}
\hline & Average & $\begin{array}{c}\text { Desviación } \\
\text { Estándar }\end{array}$ & $\begin{array}{c}\text { Coeficients } \\
\text { Cronbach's } \\
\text { Alpha } \\
\end{array}$ \\
\hline Evaluation Index & 13.19 & 13.87 & .915 \\
\hline Proclivity 1 & 25.02 & 20.80 & .920 \\
\hline Proclivity 2 & 15.37 & 16.87 & .917 \\
\hline Proclivity 3 & 16.49 & 21.73 & .962 \\
\hline Proclivity 4 & 6.70 & 12.11 & .926 \\
\hline Evaluation1 & 17.41 & 25.56 & \\
\hline Evaluation2 & 15.66 & 26.11 & \\
\hline Evaluation3 & 12.44 & 24.25 & \\
\hline Evaluation4 & 8.67 & 22.67 & \\
\hline Gender & $\mathrm{n} / \mathrm{a}$ & $\mathrm{n} / \mathrm{a}$ & \\
\hline
\end{tabular}

Table 1 presents the Cronbach Alpha coefficients for the indexes calculated in this study. The general evaluation and proclivity index coefficients for each scenario resulted in values between. 91 and. 96. This reflects a high reliability and exceeds by far the desirable minimum of at least. 70 generally accepted and defended by Nunally and Berstein (1994).

\subsection{Evaluation Index}

Table 2 shows the average of each premise of the general evaluation index ordered from less ethical to more ethical. The results show that participants considered less ethical those instances where a written document is involved in those instances where the deception occurred orally.

Table 2. Premises General Evaluation Index

\begin{tabular}{|c|c|c|}
\hline Premise & Average & $\begin{array}{l}\text { Standard } \\
\text { Deviation }\end{array}$ \\
\hline $\begin{array}{l}\text { To include false information in an } \\
\text { academic report }\end{array}$ & 3.30 & 11.03 \\
\hline $\begin{array}{l}\text { To include false information in a work } \\
\text { report }\end{array}$ & 3.45 & 10.77 \\
\hline $\begin{array}{l}\text { To include false information in a } \\
\text { resumé }\end{array}$ & 7.22 & 15.97 \\
\hline $\begin{array}{l}\text { To include false information in a credit } \\
\text { application }\end{array}$ & 7.35 & 16.90 \\
\hline $\begin{array}{l}\text { To include false information in a tax } \\
\text { report }\end{array}$ & 7.69 & 18.93 \\
\hline To cheat in a test & 8.77 & 17.87 \\
\hline to be asked to lie for someone else & 10.70 & 19.26 \\
\hline To ask somebody to lie for you & 12.35 & 21.47 \\
\hline To lie to a professor & 15.20 & 20.70 \\
\hline To offer false excuses to your boss & 16.15 & 22.02 \\
\hline $\begin{array}{l}\text { To offer false excuses to your } \\
\text { significant other }\end{array}$ & 17.30 & 24.08 \\
\hline To offer false excuses to your family & 18.15 & 24.94 \\
\hline To offer false excuses to your parents & 20.71 & 26.68 \\
\hline To let a classmate copy from your test & 20.82 & 26.24 \\
\hline To offer false excuses to your friends & 21.27 & 26.06 \\
\hline \multicolumn{3}{|c|}{$\begin{array}{l}\text { Scale: } 0 \text { \% for Unethical to } 100 \% \text { for Ethical behavior } \\
\text { Participants considered less ethical to cheat in a test } \\
\text { than to allow fellows to copy from their test. In contrast, } \\
\text { they consider less ethical when someone asks them to lie } \\
\text { than if they ask another person to lie for them. Participants } \\
\text { find it less ethical to lie to their teachers and bosses than to } \\
\text { lie to their parents, relatives and friends. They also find } \\
\text { less ethical to provide false information on academic or } \\
\text { working documents than in documents for credit } \\
\text { institutions or Government. }\end{array}$} \\
\hline
\end{tabular}

\subsection{Proclivity Indexes}

Table 3 presents the averages obtained in each of the premises of situational pressures for each scenario, ordered from the less likely to the more likely to ocurr. In all scenarios, the possibility of being discovered is among the main five conditions that minimize the likelihood of taking the action. In the same direction, the certainty that nobody will know about the questionable action is one of the last five conditions to decrease the likelihood of action. The lack of own or others' responsibility, depending on the circumstances of each case, appears to decrease the probability of execution. 
Table 3. Premises to Determine Proclivity Index by Scenario Panel A- Scenario 1 - Lie to a Professor

\begin{tabular}{|c|c|c|}
\hline $\begin{array}{l}\text { Panel A-Scenario 1 - Lle to a Protessor } \\
\text { Premises }\end{array}$ & $A=$ & Ctod \\
\hline $\begin{array}{c}\text { Premises } \\
\text { If expect an easy test. }\end{array}$ & $\frac{\text { Average }}{4.97}$ & $\frac{\text { Standard Deviation }}{18.22}$ \\
\hline even if i get caught. & 9.13 & 20.19 \\
\hline to stay resting at home & 9.59 & 21.74 \\
\hline if it is a specialization course. & 11.47 & 25.86 \\
\hline if not prepare for the test because of partying & 15.59 & 27.67 \\
\hline if other students do the same & 17.23 & 28.62 \\
\hline if an elective course. & 17.98 & 29.70 \\
\hline to have a friend tell me the test questions. & 17.99 & 29.56 \\
\hline if have good marks in the course. & 18.95 & 29.98 \\
\hline if test is perceived as difficult. & 20.02 & 30.56 \\
\hline if they will have sex with my partner. & 23.20 & 36.60 \\
\hline if close to failing the course. & 26.38 & 37.48 \\
\hline to have more time to study. & 28.93 & 34.44 \\
\hline if I know that make ups are easier. & 29.49 & 36.63 \\
\hline if this is the only time I will do it. & 35.94 & 38.03 \\
\hline If I am certain nobody will know. & 36.39 & 38.79 \\
\hline if not ready to take the test because of my job & 40.53 & 39.37 \\
\hline if I am about to take a trip & 45.02 & 40.49 \\
\hline if going to a job interview & 45.28 & 39.35 \\
\hline if that day I will make $\$ .00$, working. & 46.34 & 42.58 \\
\hline \multicolumn{3}{|c|}{ Panel B - Second Scenario - To take a test for somebody else } \\
\hline If Pedro is in the same political party as I am. & 3.14 & 13.18 \\
\hline Even if Pedro has problems in the course because of partying & 3.68 & 12.42 \\
\hline even if caught. & 3.75 & 14.16 \\
\hline if other students do the same & 3.94 & 14.06 \\
\hline even if Pedro is only an acquaintance. & 4.21 & 12.91 \\
\hline even if asked before. & 5.21 & 16.21 \\
\hline if offers to wash my car. & 5.78 & 18.24 \\
\hline if Pedro goes to the same church as me. & 6.76 & 19.32 \\
\hline if Pedro is outgoing. & 7.03 & 19.08 \\
\hline even if there is no risk of Pedro loosing his scholarship. & 7.98 & 19.78 \\
\hline if offered sex. & 8.87 & 23.94 \\
\hline if Pedro has to work and has no time to study. & 15.66 & 26.42 \\
\hline instead of helping him study. & 16.35 & 30.32 \\
\hline if the bribe is higher than $\$ .00$. & 21.57 & 34.31 \\
\hline if this is the first time he asks me for this kind of favor & 22.50 & 33.21 \\
\hline if certain that no one will know. & 27.99 & 37.06 \\
\hline if offered $\$ .00$ & 31.97 & 40.22 \\
\hline if a close relative. & 36.32 & 39.16 \\
\hline If Pedro is my friend. & 37.10 & 39.03 \\
\hline If Pedro is responsible with his studies but does not understand the particular material & 37.66 & 39.68 \\
\hline \multicolumn{3}{|l|}{ Panel C - Third Scenario - False information on Resume } \\
\hline even if caught. & 4.55 & 13.58 \\
\hline to impress my friends/relative with the new job. & 7.06 & 19.27 \\
\hline if others do it & 9.88 & 23.17 \\
\hline if I have done it before. & 10.49 & 23.72 \\
\hline if a family enterprise. & 13.26 & 26.32 \\
\hline if expect to be on the job for a short time. & 13.62 & 26.02 \\
\hline if a high responsibility job. & 14.30 & 27.96 \\
\hline if offers a good retirement package & 14.68 & 27.80 \\
\hline if business known by its social responsibility. & 15.66 & 29.65 \\
\hline if working abroad is possible. & 16.51 & 30.11 \\
\hline if a multinational company. & 18.71 & 30.79 \\
\hline if this is the only time. & 18.75 & 32.56 \\
\hline if there is opportunity to travel. & 19.15 & 32.24 \\
\hline if not much mental effort is required. & 19.97 & 33.00 \\
\hline if the first step to higher positions. & 20.92 & 33.15 \\
\hline if it means a challenge. & 21.11 & 33.63 \\
\hline if good maginal benefits & 26.29 & 35.92 \\
\hline if it pays for graduate studies. & 27.06 & 36.42 \\
\hline if certain that nobody will know. & 30.03 & 39.10 \\
\hline if it means a salary of at least $\$ .00$ & 33.59 & 40.14 \\
\hline \multicolumn{3}{|l|}{$\begin{array}{l}\text { Panel D - Fourth Scenario - Falsify a work document } \\
\end{array}$} \\
\hline Even when Maria did not achieve the quota for being partying. & 1.23 & 6.08 \\
\hline even if caught. & 1.51 & 8.12 \\
\hline even when there is no risk of Maria loosing the bonus. & 1.62 & 7.47 \\
\hline if Maria is from the same political party & 1.67 & 8.83 \\
\hline even when asked before. & 2.08 & 9.06 \\
\hline even if Maria is only an acquaintance. & 2.37 & 10.12 \\
\hline if offered lunch. & 2.42 & 9.02 \\
\hline if Maria goes to my church. & 2.51 & 11.55 \\
\hline if others do it. & 3.96 & 12.89 \\
\hline if I like Maria. & 6.25 & 17.95 \\
\hline instead of mentoring her to do better next month. & 6.54 & 18.83 \\
\hline if this is the first time she asks & 7.31 & 18.98 \\
\hline if offered sex. & 8.49 & 23.68 \\
\hline if Maria has personal problems that affect her performance at work. & 10.68 & 23.14 \\
\hline if the bonus is greater than $\$ .00$. & 10.86 & 24.83 \\
\hline if Maria is my friend. & 11.31 & 23.44 \\
\hline if offers $\$ .00$ & 11.37 & 26.72 \\
\hline if certain nobody will know. & 11.44 & 25.58 \\
\hline if a close relative. & 14.39 & 27.27 \\
\hline if Maria is responsible with her job but was sick part of the time & 15.92 & 28.71 \\
\hline
\end{tabular}


The fact that other people are used to do the same, or that the same situation has been experienced previously, do not seem to tempt the participants to act in a questionable way. The friendship and family ties appear to be good reasons for crossing the border of ethical behavior to the unethical, but not belonging to the same political party. Economic rewards or compliance at work appear to be frequent justifications for unethical behavior. Sexual rewards do not seem to affect the decisions of the participants.

\subsection{Hypotheses Results}

Hierarchical regressions were performed for dependent variables evaluations and the proclivity index for each scenario. This method allows that variance changes can be attributed to each series of independent variables. Thus, the effect of each added variable is clear. Standard F test were used to determine the significance of each variable to variance $Y$. The variables were entered in the following: (1) the evaluation of the corresponding scenario (2) the general evaluation index (3) evaluations of previous scenarios and (4) gender. For the evaluation index regressions the order was: (1) the proclivity index of the corresponding scenario (2) the general evaluation index (3) evaluations of previous scenarios and (4) gender. The coefficient of determination, $\mathrm{R}^{2}$, and the adjusted $\mathrm{R}^{2}$ were calculated. Table 4 presents the Adjusted Beta ( $\beta$ ) coefficients and their significance resulting from the regression of evaluation by scenario. Table 5 presents the results of the regression of the proclivity index as a dependent variable.

Table 4. Adjusted Coeficients $(\beta)$ and the Resultant Determinants of the Regression for the evaluation by scenario

\begin{tabular}{|c|c|c|c|c|c|c|c|c|c|c|c|c|c|c|c|c|}
\hline \multirow{3}{*}{ Independent Variables } & \multicolumn{16}{|c|}{ Dependent Variable: Evaluation } \\
\hline & \multicolumn{4}{|c|}{ Scenario I } & \multicolumn{4}{|c|}{ Scenario II } & \multicolumn{4}{|c|}{ Scenario III } & \multicolumn{4}{|c|}{ Scenario IV } \\
\hline & 1 & 2 & 3 & 4 & 1 & 2 & 3 & 4 & 1 & 2 & 3 & 4 & 1 & 2 & 3 & 4 \\
\hline Evaluation Index & & .196 & .196 & & & ns & ns & ns & & ns & ns & Ns & & .170 & ns & ns \\
\hline EvaluationI & & & & & & & .278 & .278 & & & .226 & .225 & & & ns & ns \\
\hline EvaluationII & & & & & & & & & & & .369 & .367 & & & .346 & .346 \\
\hline EvaluationIII & & & & & & & & & & & & & & & .357 & .358 \\
\hline EvaluationIV & & & & & & & & & & & & & & & & \\
\hline Proclivity 1 & .485 & .387 & .387 & & & & & & & & & & & & & \\
\hline Proclivity 2 & & & & & .252 & .216 & .191 & .189 & & & & & & & & \\
\hline Proclivity 3 & & & & & & & & & .367 & .329 & .277 & .273 & & & & \\
\hline Proclivity 4 & & & & & & & & & & & & & .283 & .214 & $\begin{array}{c}.113 \\
(.023)\end{array}$ & $\begin{array}{c}.117 \\
(.022)\end{array}$ \\
\hline Gender & & & ns & & & & & ns & & & & ns & & & & \\
\hline $\mathbf{R}^{2}$ & .235 & .264 & .264 & & .064 & .072 & .137 & .137 & .135 & .141 & .356 & .358 & .080 & .104 & .457 & .458 \\
\hline$\Delta \mathbf{R}^{2}$ & .235 & .029 & .000 & & .064 & .008 & .065 & .000 & .135 & .006 & .215 & .002 & .080 & .024 & .353 & .001 \\
\hline$P$ value & .000 & .000 & .000 & & .000 & .000 & .000 & .000 & .000 & .000 & .000 & .000 & .000 & .000 & .000 & .000 \\
\hline Adjusted $\mathbf{R}^{2}$ & .233 & .259 & .256 & & .060 & .065 & .128 & .125 & .132 & .135 & .346 & .347 & .077 & .098 & .447 & .446 \\
\hline
\end{tabular}

All Beta coefficients are significant at $\mathrm{p}<.010$, when not significant it appears in parenthesis

$\mathrm{ns}=$ non significant coefficient at $\mathrm{p}<.050$

Table 5. Adjusted Coefficients ( $\beta$ ) and the Resultant Determinants of the Regression Proclivities by Scenario

\begin{tabular}{|c|c|c|c|c|c|c|c|c|c|c|c|c|c|c|c|c|}
\hline \multirow{3}{*}{$\begin{array}{l}\text { Independent } \\
\text { Variables }\end{array}$} & \multicolumn{16}{|c|}{ Dependent Variable - Proclivity } \\
\hline & \multicolumn{4}{|c|}{ Scenario I } & \multicolumn{4}{|c|}{ Scenario II } & \multicolumn{4}{|c|}{ Scenario III } & \multicolumn{4}{|c|}{ Scenario IV } \\
\hline & 1 & 2 & 3 & 4 & 1 & 2 & 3 & 4 & 1 & 2 & 3 & 4 & 1 & 2 & 3 & 4 \\
\hline Evaluation Index & & .370 & .361 & & & .342 & .171 & .164 & & .378 & $\begin{array}{c}.137 \\
(.011)\end{array}$ & $\begin{array}{c}.137 \\
(.011)\end{array}$ & & .358 & ns & ns \\
\hline EvaluationI & .485 & .341 & .337 & & & & & & & & & & & & & \\
\hline EvaluationII & & & & & .252 & .191 & .173 & .167 & & & & & & & & \\
\hline EvaluationIII & & & & & & & & & .367 & .280 & .235 & .236 & & & & \\
\hline EvaluationIV & & & & & & & & & & & & & .284 & .192 & $\begin{array}{l}.092 \\
(.049)\end{array}$ & ns \\
\hline Proclivity 1 & & & & & & & .346 & .332 & & & .322 & .323 & & & ns & ns \\
\hline Proclivity 2 & & & & & & & & & & & .236 & .239 & & & .320 & .298 \\
\hline Proclivity 3 & & & & & & & & & & & & & & & .314 & .315 \\
\hline Proclivity 4 & & & & & & & & & & & & & & & & \\
\hline Gender & & & ns & & & & & $\begin{array}{l}-.116 \\
(.025)\end{array}$ & & & & ns & & & &. \\
\hline $\mathbf{R}^{2}$ & .235 & .352 & .358 & & .064 & .177 & .266 & .279 & .135 & .270 & .434 & .435 & .081 & .200 & .465 & .482 \\
\hline$\Delta \mathbf{R}^{2}$ & .235 & .117 & .006 & & .064 & .113 & .089 & .013 & .135 & .135 & .164 & .001 & .081 & .119 & .265 & .017 \\
\hline$P$ value & .000 & .000 & .000 & .000 & .000 & .000 & .000 & .000 & .000 & .000 & .000 & .000 & .000 & .000 & .000 & .000 \\
\hline Adjusted $\mathbf{R}^{2}$ & .233 & .347 & .352 & & .06 & .171 & .258 & .269 & .132 & .265 & .426 & .425 & .077 & .195 & .455 & .471 \\
\hline
\end{tabular}

All Beta coefficients are significant at $\mathrm{p}<.010$, when not significant it appears in parenthesis $\mathrm{ns}=$ non significant coefficient at $\mathrm{p}<.050$ 
First Hypothesis - The moral evaluation will be correlated with the intention to act in a given situation.

The results of both regression models provide evidence of the correlation of evaluation and the intention to act. In each model, the only independent variable captures from six to twenty-three percent of the variance of the corresponding dependent variable. This provides evidence that supports Jones' model, suggesting that the more ethical the evaluation of the situation, the higher the probability of the person acting ethically and vice versa. However, contrary to expected, the coefficient of determination, $\mathrm{R}^{2}$ decreases by scenario, implying that the evaluation loses explanatory power for the intention to act as the moral intensity of the situation increases. This finding contradicts the theoretical propositions in Jones' model.

The adjusted determination coefficients $\left(\mathrm{R}^{2}\right)$ of both regression models captured an acceptable percentage of variance. The regressions that examine the Jones model and the other proposed variables, explain from 27 to 47 percent of the phenomenon, while the ones examining the dissonance theory explain 13 to 45 percent. This suggests that although Jones model seems to better explain the ethical decision-making process, the theory of cognitive dissonance appears to be an equally satisfactory explanation.

Second Hypothesis: The general evaluation is positively correlated with the specific evaluation of a specific situation.

The results show that the general evaluation is significant on the first and fourth stage. In the fourth scenario this evaluation loses its significance when entered previous concrete evaluations to the regression equation. Therefore the results do not support this hypothesis. This finding has important implications for the teaching of ethics which will be discussed later.

Third Hypothesis: The general evaluation is positively correlated with the intention to act in a given situation.

The inclusion of this variable to each scenario regression model resulted in a significant change in the coefficient of determination which provides evidence of support for the hypothesis. However, in the last two scenarios its significance declined or disappeared entirety when other variables were included in the model. This suggests that the evidence provides a rather moderate support for the hypothesis.

Fourth Hypothesis: The evaluation of lower moral intensity situations is positively correlated with the evaluation of a situation of greater moral intensity.

In the third step of the hierarchical regressions where evaluations were the dependent variable, evaluations of earlier scenarios (lower moral intensity) were added to determine its impact on the corresponding evaluation. This step resulted in a significant increase in the adjusted coefficient of determination in all scenarios providing support for this hypothesis. The adjusted beta coefficients suggest that individuals tend to use up to two previous evaluations to make their ethical judgment. The most recent specific evaluation is the relatively more important variable used to make the ethical judgment.

Fifth Hypothesis: The intention to act unethically is positively correlated with the intention to act unethically in situations of greater moral intensity.

In the third step of the hierarchical regression where the proclivity index was the dependent variable, proclivity indexes of previous scenarios (less moral intensity) were added to determine its impact on the corresponding proclivity index. This step resulted in a significant increase in the adjusted coefficient of determination in all scenarios providing support to the fifth hypothesis. The adjusted beta coefficients suggest that individuals tend to use their intention to act in two previous situations to decide how to act in the current situation. The more ethical his intention in previous situations, the more ethical his intention to act in the present situation, and vice versa.

Sixth Hypothesis: Men are more willing to give in to pressures from the situation, making them more likely to have an unethical behavior than women.

The last step of the hierarchical regression added the gender of the participants to determine its impact on the proclivity index or evaluation. In the case of the regressions where the proclivity index was the dependent variable mixed results were obtained. Scenarios two and four show a significant increase in the $\mathrm{R}^{2}$ and the presence of negative significant adjusted beta coefficients. This suggests that men are more likely to act unethically than women, as proposed in the sixth hypothesis. There were not significant increases in the $\mathrm{R}^{2}$ or significant beta coefficients for the first and third scenarios. This suggests that gender does not affect the intention to act in one way or another. Therefore, the results suggest that men are more likely to behave unethically than women in some particular situations, providing partial support to the fourth scenario. It is important to note that the two scenarios with significant differences are the two where the actor falsifies documents (a test and a sales report) for the benefit of a colleague. It might be interpreted that men have a stronger sense of solidarity or empathy than women.

Seventh Hypothesis: Gender does not affect the evaluation of an ethical conflict.

The inclusion of gender in the regressions where evaluation was the dependent variable shows no significant changes in the adjusted coefficient of determination or in the significant beta coefficients. This provides support to the last hypothesis, suggesting that men and women assess situations in a similar way.

\subsection{Gender Comparisons}

In addition to the previously discussed regressions, Whitney U tests were performed to identify differences in the specific premises of each scenario. These results provide additional support evidence to the fourth and fifth hypotheses.

\subsection{Evaluation Index}

The only significant difference, between men and women, found in the premises of general evaluation was to include false information in a credit application. Although both groups evaluated it as quite non ethical, women assessed it less ethical (4.93) than men (10.74). This result confirms that gender does not seem to affect the assessments individuals make of ethical conflicts.

\subsection{Proclivity Indexes}

Significant differences were identified in the averages obtained in about half of the premises of each scenario, 
which are presented in Table 6 listed by their significance. In all the premises, regardless of the magnitude or level of significance, men appear to be more likely to act unethically. Men are more likely than women to cross the border between the ethical and unethical behavior under various circumstances such as the existence of any economic reward or sexual intimacy.

Table 6. Premises with significant differences by Gender

\begin{tabular}{|c|c|c|c|c|}
\hline \multicolumn{5}{|c|}{ Panel A - Scenario 1 - Mentir a Profesor } \\
\hline Premises & MEN & WOMEN & Differnce & p Value \\
\hline If that day will have sex with partner & 44.65 & 9.26 & 35.39 & .000 \\
\hline if other students do the same & 24.08 & 12.88 & 11.20 & .001 \\
\hline i I have a good score in the class. & 23.37 & 16.01 & 7.36 & .012 \\
\hline If only this time & 42.03 & 31.60 & 10.43 & .015 \\
\hline i fan elective course. & 22.80 & 14.63 & 8.17 & .017 \\
\hline if makeup tests are easier. & 36.24 & 25.23 & 11.01 & .017 \\
\hline To stay at home resting & 12.08 & 8.01 & 4.07 & .021 \\
\hline for a friend to tell me the exam questions. & 22.92 & 14.85 & 8.07 & .024 \\
\hline even if caught. & 11.96 & 6.93 & 5.03 & .027 \\
\hline if close to fail in the course. & 31.79 & 22.66 & 9.13 & .037 \\
\hline \multicolumn{5}{|c|}{ Panel B- Scenario 2 - To do the test for another person } \\
\hline if offered sex. & 20.01 & 1.31 & 18.70 & .000 \\
\hline if offered money in exchange. & 43.28 & 24.73 & 18.55 & .000 \\
\hline if a close relative. & 44.10 & 30.84 & 13.26 & .006 \\
\hline if the first time somebody asks me. & 27.45 & 19.14 & 8.31 & .009 \\
\hline if certain that nobody will know. & 34.26 & 23.80 & 10.46 & .028 \\
\hline If Pedro is my friend. & 42.74 & 33.03 & 9.71 & .028 \\
\hline even when Pedro has problems in the course because of partying. & 6.09 & 1.83 & 4.26 & .050 \\
\hline \multicolumn{5}{|c|}{ Panel C - Scenario 3 - False information in the Resume } \\
\hline if it is the first step for advancement. & 27.28 & 16.46 & 10.82 & .002 \\
\hline to impress friends and relatives with the job & 12.20 & 3.73 & 8.47 & .006 \\
\hline until a better job is found. & 20.23 & 9.29 & 10.94 & .010 \\
\hline if it is a multinational organization. & 22.85 & 16.09 & 6.76 & .011 \\
\hline if only this time. & 24.91 & 14.67 & 10.24 & .011 \\
\hline if graduate studies are paid. & 32.36 & 23.51 & 8.85 & .025 \\
\hline if done previuosly. & 14.73 & 7.77 & 6.96 & .026 \\
\hline if certain that nobody will know. & 36.11 & 26.10 & 10.01 & .032 \\
\hline even if caught. & 7.23 & 2.53 & 4.70 & .034 \\
\hline if there is opportunity to work abroad. & 22.33 & 12.78 & 9.55 & .040 \\
\hline if no challenge. & 24.54 & 16.96 & 7.58 & .043 \\
\hline \multicolumn{5}{|c|}{ Panel D - Scenario 4 - Falsify work document } \\
\hline if I like Maria. & 12.32 & 2.30 & 10.02 & .000 \\
\hline if certain that nobody will know. & 18.40 & 6.91 & 11.49 & .002 \\
\hline if Maria is my friend. & 16.74 & 7.78 & 8.96 & .003 \\
\hline If the first time. & 11.76 & 4.42 & 7.34 & .006 \\
\hline If Maria is in the same political party. & 3.59 & .42 & 3.17 & .006 \\
\hline even if caught. & 2.91 & .59 & 2.32 & .013 \\
\hline If Maria is responsible but was sick & 22.01 & 11.95 & 10.06 & .027 \\
\hline if offered lunch. & 4.71 & .93 & 3.78 & .027 \\
\hline If Maria has personal problems that limit her performance. & 15.27 & 7.72 & 7.55 & .028 \\
\hline instead of mentoring for other alternatives next month & 9.61 & 4.54 & 5.07 & .044 \\
\hline
\end{tabular}

Men tend to relax their behavior if a relative, friend or a member of its own political party is implicated. Whereas engage in an unethical act only once or the certainty that nobody will know seem to be enabling circumstances. Fear of being discovered does not seem to stop males to cross the line.

\subsection{Evaluations and Proclivity Indexes by Scenario}

Finally, evaluations and proclivity indexes of men and women were compared, which are presented in the following table. As the moral intensity of situations increases, both men and women evaluated them as less ethical. Women tend to evaluate them, generally less ethically than men, but none of the differences in assessment were statistically significant. The fifth hypothesis is therefore supported.
Table 7. Evaluation Averages and Proclivity Index by Gender

\begin{tabular}{ccccc}
\hline Índexes & Men & Women & Difference & p value \\
\hline EvaluationScenario 1 & 20.08 & 15.65 & 4.43 & .621 \\
EvaluationScenario 2 & 17.91 & 13.96 & 3.95 & .204 \\
EvaluationScenario 3 & 16.25 & 9.96 & 6.29 & .145 \\
EvaluationScenario 4 & 11.41 & 6.88 & 4.53 & .195 \\
EvaluationGeneral & 15.34 & 11.73 & 3.61 & .079 \\
Proclivity 1 & 29.02 & 22.31 & 6.71 & .010 \\
Proclivity 2 & 19.47 & 12.55 & 6.92 & .001 \\
Proclivity 3 & 19.88 & 14.22 & 5.66 & .007 \\
Proclivity 4 & 10.68 & 4.10 & 6.58 & .000
\end{tabular}

Both men and women are less likely to act unethically as the moral intensity of the situation increases, which supports Jones' model. However, women are less likely to act unethically than men in all circumstances. All differences were statistically significant which supports the fourth hypothesis of this study. 


\section{Discussion of Results}

The results strongly support five hypotheses, a sixth hypothesis obtained partial support and one was not supported by the evidence. The first hypothesis states a relationship between the evaluation and intention to act step without showing the direction. The results support the dynamism and bidirectionality of the proposed model. The analysis of the adjusted coefficients of determination $\left(\mathrm{R}^{2}\right)$ reveals that both, the evaluation and the intention to act in a particular situation are multidimensional phenomena, affected by previous assessments and behavior. The general evaluation seems to have no impact on the assessments of specific situations. This implies that individuals do not develop morally in a vacuum. On the contrary, moral development is the result of accumulated learning in concrete and practical situations. This result poses a major challenge for educational institutions in terms of contents, approaches and educational methodologies of the ethics courses offered to students of business administration. It is imperative to continue researching how students learn ethics, instead of how to teach the topic.

Although the results suggest, in general terms, that participants do not consider deception as ethical behavior and would not act in this way, the study identifies situations and circumstances in which participants are willing to cross the border from ethical to unethical behavior. An important finding is that participants perceive that deceiving, parents, relatives, friends or significant others is not too objectionable. This means that if in the most important personal relations, that should constitute refuge and support for individuals there is room for deception, they are not built on a robust foundation of trust, respect and tolerance. This implies a tendency towards individualism and perhaps worse, towards isolation from other adults. If living within societal boundaries is not an objective neither will be to behave ethically. Contradictorily, friendship and family ties have proved to be frequent justifications to behave unethically. Therefore, new educational models have to educate students not only to live in society, but to help them identify in what kind of society they want to live and how they can contribute to achieve it.

Another important finding is that one of the strong reasons to behave ethically is the fear to be discovered, and to behave in an unethical way it is the certainty that nobody will know. This implies a vision focused on the immediate consequences and, even more, the decision is based on the external factors. This portrays a malleable and submissive generation of young adults, willing to follow the rules imposed from the outside, but with little inner strength to promote their own convictions. It is imperative that new models of study in business administration educate students to think and act independently based on their beliefs and values.

The financial rewards are an important factor to behave unethically. This implies a dangerous trend towards the dehumanization of individuals. It is easy to argue that each person has a price. However, this result also points to a society living beyond its means and expecting the easy reward. As long as individuals have expectations that the system is not able to satisfy, there will be space for unethical behavior. Then, the models of study have to train students to evaluate and assess the strengths and limitations, own and of others, which allows them to maximize their potential and live a full life.

This study provides supporting evidence to argue that men and women assess situations similarly, but may differ in the way they act. It seems that men tend to be more prone to unethical behavior. This trend may be explained by the possibility that men have a stronger sense of empathy and solidarity than women. Another plausible explanation may be that given the broader space of action of men, (while women is often limited to the domestic environment) they play behaviors associated with the family context in more public environments. This would imply that women have a different perception of the meaning of public and private, the affective distance and the familiar context, adjusting their behavior according to the context where the action is executed. Given the progressive and growing inclusion of women in the public arena, educational institutions have the great challenge of incorporating the perceptions and needs of this sector to their educational models.

\section{Conclusions}

This study achieved the three objectives previously indicated. First, it not only identified various situational pressures that can affect the behavior of individuals, but also determined the relative strength of them. Second, this study proposed and tested a dynamic and bidirectional decision-making model integrating the theory of cognitive dissonance and the model proposed by Jones. It found clear and strong evidence of support for five of the seven proposed hypotheses and partial support for another. This study identified that the evaluations, but most of all, the previous actions of individuals, affect the evaluation and action of current situations. Third, the study identified significant differences in the responses of men and women. This study provides evidence to support the argument that men and women evaluated ethical conflicts similar but differ in their intention to act.

Any study confronts limitations which must be informed. The sample was not randomly selected, thus results cannot, and have not been, generalized to the population. The sample consisted of business students that not necessarily had work experience, so their responses to the scenarios where work situations are presented may not reflect real experiences. That could affect the results.

Regardless of the progress made in ethics research, there are many questions to answer. Studies focused in understanding the ethical decision-making process of individuals that may explain and predict the behavior are still needed. This study opens new avenues of research. It is necessary to validate the measurement instrument in other contexts and with other scenarios. More research is needed to explain the factors that affect the ethical behavior of men and women and their implications in the process of education and socialization for both. Furthermore, there is the need to develop new educational methodologies for the ethics teaching-learning process in business schools to prepare the students to build a society conducive to the full development of individuals. Last but not least, the results of this study deserve to be tested in future studies to see if they can be generalized to other groups. 


\section{References}

[1] Alleyne P., D. Devonish, J. Nurse, C. Cadogan-McClean. 2006. Perceptions of Moral Intensity Among Undergraduate Accounting Students in Barbados. Journal of Eastern Caribbean Studies 31, no. 3 (September 1): 1-26.

[2] Ajzen, I. 1991. The theory of planned behavior. Organizational Behavior and Human Decision Processes 50: 179-211.

[3] Ajzen, I., and M. Fishbein. 1980. Belief, attitude, intention and behavior: An introduction to theory and research. Reading, MA: Addison-Wesley.

[4] Barnett, T, and S. Valentine. 2004. Issue contingencies and marketers' recognition of ethical issues, ethical judgments and behavioral intentions. Journal of Business Research 57, no. 4 (April 1): 338-346.

[5] Bay, D. 2002. A critical evaluation of the use of the DIT in accounting ethics research. Critical Perspectives on Accounting 13:159-77.

[6] Becker, H., \& Fritzsche D. 1987. Business ethics: A cross-cultural comparison of managers' attitudes. Journal of Business Ethics 6:189-202.

[7] Bommer, M., C. Gratto, J. Gravander, and M. Tuttle. 1987. A behavioral model of ethical and unethical decision-making. Journal of Business Ethics 6: 265-80.

[8] Bouville, M. (2008) Whistle Blowing and Morality. Journal of Business Ethics 81: 579-585.

[9] Carlson D., M. Kacmar and L. Wadsworth. 2002. The impact of moral intensity dimensions on ethical decision making: Assessing the relevance of orientation. Journal of Managerial Issues 14, no. 1 (April 1): 15-30.

[10] Chia, A, Mee L. 2000. The effects of issue characteristics on the recognition of moral issues. Journal of Business Ethics 27, no. 3 (October 1): 255-269.

[11] Cohen, J., L. Pant, and D. Sharp. 1998. The effect of gender and academic discipline diversity on the ethical evaluations, ethical intentions and ethical orientation of potential public accounting recruits. Accounting Horizons 12:250-70.

[12] Comer, D.and G. Vega. 2008. Using the PET Assessment Instrument to Help Students Identify Factors that Could Impede Moral Behavior. Journal of Business Ethics 77, no. 2 (January 1): 129.

[13] Coram, P., A. Glavovic, J. Ng and D.Woodliff. 2008. The Moral Intensity of Reduced Audit Quality Acts. Auditing 27, no. 1 (May 1): $127-149$.

[14] Davis M., N. Brown Johnson and D. Ohmer. 1998. Issuecontingent effects on ethical decision making: A cross-cultural comparison. Journal of Business Ethics 17, no. 4 p 373-389

[15] Dubinsky, A., and B. Loken. 1989. Analyzing ethical decisionmaking in marketing. Journal of Business Research 19:83-107.

[16] Ferrell, O., and L. Gresham. 1985. A contingency framework for understanding ethical decision-making in marketing. Journal of Marketing 49 (Summer): 87-96.

[17] Ferrell, O., L. Gresham, and Fraedrich, J. 1989. A synthesis of ethical decision models for marketing. Journal of Macromarketing 9:55-64.

[18] Festinger, L. (1957). A theory of cognitive dissonance. Evanston, IL: Row, Peterson

[19] Frey, B. 2000. The impact of moral intensity on decision making in a business context. Journal of Business Ethics 1 26, no. 3 (August 1): 181-195.

[20] Gilligan, C. 1982. In a different voice. Cambridge, MA: Harvard University Press.

[21] Gump, L., and R. Baker. 2000. Cultural and gender differences in moral judgment: A study of Mexican Americans and AngloAmericans Hispanic Journal of Behavioral Science 22: 78-94.

[22] Honeycutt, E., J. Siguaw, and T. Hunt. 1995. Business ethics and job related constructs: A cross-cultural comparison of automotive salespersons. Journal of Business Ethics 14: 235-48.

[23] Hunt, S., and S. Vitell. 1986. A general theory of marketing ethics. Journal of Macromarketing 6 (Spring): 5-16.

[24] Karnes, A., Sterner J., Welker R., \& Wu F. 1989. A bicultural study of independent auditors' perceptions of unethical business practices. International Journal of Accounting 24.

[25] Kelley, P.and D. Elm. 2003. The Effect of Context on Moral Intensity of Ethical Issues: Revising Jones's Issue-Contingent Model. Journal of Business Ethics 48, no. 2 (December 1): 139154.
[26] Kohlberg, L. 1976. Moral stages and moralization: The cognitivedevelopmental. In Moral development and behavior: Theory, research and social issues, ed. T. Lickona, New York: Holt, Rinehart and Winston.

[27] Jones, T. 1991. Ethical decision-making by individuals in organizations: An issue-contingent model. Academy of Management Review 16: 366-95.

[28] Leitsch, D. 2006. Using dimensions of moral intensity to predict ethical decision-making in accounting. Accounting Education 15, no. 2 (June 1): 135-149.

[29] Leitsch, D.. 2004. Differences in the Perceptions of Moral Intensity in the Moral Decision Process: An Empirical Examination of Accounting Students. Journal of Business Ethics 53, no. 3 (September 1): 313-323.

[30] López-Paláu, S. 2000. Multidimensional ethics scale usefulness to explain and predict ethical evaluations and intentions of Latin American accountants. Paper presented at the ABO Research Conference, Chicago.

[31] Paláu S L. 2001. Ethical evaluations, intentions and orientations of accountants: Evidence from a cross-cultural examination. International Advances in Economic Research 7:351-64.

[32] López-Paláu S. 2006. Culture Effects in the Ethical DecisionMaking Process of Latin American Accountants. Doctoral Dissertation Texas Pan American University.

[33] López-Paláu S 2008. Fundamentos Morales de las Evaluaciones Éticas de los Contadores. Forum Empresarial Vol. 13 Num 1 Mayo.

[34] López Paláu, S. and B. Rivera Cruz (2007). Ética en las Escuelas de Negocios: Estudio Empírico de Puerto Rico, X Asamblea de la Asociación Latinoamericana de Facultades y Escuelas de Contaduría y Administración (ALAFEC) Dominican Republic, November 28-31.

[35] Luthar, Harsh and Karri Ranjan. 2005. Exposure to Ethics Education and the Perception of Linkage Between Organizatinal Ethical Behavior and Business Outcomes. Journal of Business Ethics. 61: 353-368.

[36] Marnburg, E. 2001. The questionable use of moral development theory in studies of business ethics: Discussion and empirical findings. Journal of Business Ethics 32: 275-83.

[37] May, D and K. Pauli. 2002. The role of moral intensity in ethical decision making. Business and Society 41, no. 1 (March 1): 84117.

[38] McGee, R. and López-Paláu, S. 2007 (a) The Ethics of Tax Evasion: An Empirical Study of Puerto Rican Opinion VIII Annual Conference of National Business and Economic Society, Rio Grande, Puerto Rico, March.

[39] McGee R W, Paláu S L. 2008 Tax Evasion and Ethics: A Comparative Study of the USA and Four Latin American Countries in Taxation and Public Finance in Transition and Developing Economies. Springer pp 185-224.

[40] McGee, R; López-Paláu, S. and Polanco E. (2007). ¿Es ética la evasión de impuestos? Estudio Empírico de Opinión de República Dominicana X Asamblea de la Asociación Latinoamericana de Facultades y Escuelas de Contaduría y Administración (ALAFEC) Dominican Republic, November 28-31,. Listed on SSRN's Top Ten download list for AE: Business \& Professional Ethics.

[41] McMahon, J, R. Harvey. 2006. An Analysis of the Factor Structure of Jones' Moral Intensity Construct. Journal of Business Ethics 64, no. 4 (April 1): 381-404.

[42] McMahon, J, R. Harvey. 2007. Psychometric Properties of the Reidenbach-Robin Multidimensional Ethics Scale. Journal of Business Ethics 72, no. 1 (April 1): 27-39.

[43] Moser, M. 1988 Ethical Conflict at Work: A Critique Of The Literature and Recommendations for Future Research. Journal of Business Ethics. Vol. 7, Iss. 5

[44] Ng, J., G.White, A. Lee and A. Moneta. 2009. Design and Validation of a Novel New Instrument for Measuring the Effect of Moral Intensity on Accountants' Propensity to Manage Earnings. Journal of Business Ethics 84, no. 3 (February 1): 367-387.

[45] Nill A, J. Schibrowsky. 2005. The Impact of Corporate Culture, the Reward System, and Perceived Moral Intensity on Marketing Students' Ethical Decision Making. Journal of Marketing Education 27, no. 1 (April 1): 68-80.

[46] Nunnally, J and I.H. Berstein. 1994. Psychometric Theory. $3^{\text {rd }}$ Edition. New York: McGraw-Hill.

[47] Paolillo, J. and S. Vitell. 2002. An empirical investigation of the influence of selected personal, organizational and moral intensity 
factors on ethical decision making. Journal of Business Ethics 135 , no. 1 p 65-74.

[48] Patterson, D. 1994. A model of ethical/unethical decision-making by auditors in the big six accounting firms. PhD diss., Georgia State University.

[49] Reiter, S. 1996. The Kohlberg-Gilligan controversy: Lessons for accounting ethics education. Critical Perspectives on Accounting 7: 33-54.

[50] Rest, J. 1986. Moral development: Advances in theory and practice. New York: Praeger.

[51] Rivera Cruz B. y S. López Paláu 2008 Codes of Ethics: The Case of the Business Schools. Clute Institute Conference, San Juan, Puerto Rico. March. Best paper award.

[52] Roxas, Maria L. \& Jane Y. Stoneback. (2004). The Importance of Gender Across Cultures in Ethical Decision-Making. Journal of Business Ethics 50: 149-165.

[53] Singh Jatinder J, Scott J Vitell, J. Al-Khatib, I. Clark III. 2007. The Role of Moral Intensity and Personal Moral Philosophies in the Ethical Decision Making of Marketers: A Cross-Cultura Comparison of China and the United States. Journal of International Marketing 15, no. 2 (June 1): 86.

[54] Singhapakdi, A., S. Vitell, and O. Leelakulthanit. 1994. A crosscultural study of moral philosophies, ethical perceptions and judgments: A comparison of American and Thai marketers. International Marketing Review 11: 65-79.

[55] Singhapakdi, A. and Scott J Vitell, G.Franke 1999. Antecedents, consequences, and mediating effects of perceived moral intensity and personal moral philosophies. Academy of Marketing Science Journal. Vol. 27, Iss. 1.

[56] Singhapakdi, A, Vitell, S, Kraft, K. 1996. Moral intensity and ethical decision-making of marketing professionals Journal of Business Research. Vol. 36, Iss. 3.

[57] Smith, A., and E. Hume. 2001. Ethics in accounting: Does culture matter? American Society of Business and Behavioral Sciences Conference (February).

[58] Smith A, Hume E C. 2005. Linking Culture and Ethics: A Comparison of Accountants' Ethical Belief Systems in the
Individualism/Collectivism and Power Distance Contexts. Journal of Business Ethics 62: 209-220.

[59] Stedham, Yvonne, Yamamura, Jeanne H., Beekun, Rafik I. (2007) Gender Differences in Business Ethics: Justice and Relativist Perspectives. Business Ethics: A European Review; Vol. 16 Issue 2, p163-174, 12p

[60] Sweeney B. and F. Costello. 2009. Moral Intensity and Ethical Decision-making: An Empirical Examination of Undergraduate Accounting and Business Students. Accounting Education 18, no. 1 (February 1): 75.

[61] Teoh, H. Y., D. P. Serang, \& Lim C. C. 1999. Individualismcollectivism cultural differences affecting perceptions of unethical practices: Some evidence from Australian and Indonesian accounting students. Teaching Business Ethics 3: 137-53.

[62] Thomas, S. 1986. Moral judgment, behavior, decision-making and attitudes. Moral development: Advancement in research and theory, ed. J. Rest, 133-75. New York: Praeger.

[63] Trevino, L. K.: 1986, 'Ethical Decision Making in Organizations: A Person-Situation Interactionist Model', Academy of Management Review 11, 601-617.

[64] Tsalikis, J., and D. Fritzsche. 1989. Business ethics: A literature review with a focus on marketing ethics. Journal of Business Ethics 8: 695-743.

[65] Tsalikis, J., B Seaton and P. Shepherd. 2008. Relative Importance Measurement of the Moral Intensity Dimensions. Journal of Business Ethics 80, no. 3 (July 1): 613-626.

[66] Valentine, S. and T. Rittenburg. 2007. The Ethical Decision Making of Men and Women Executives in International Business Situations. Journal of Business Ethics 71. 125-134.

[67] Vitell, S and A. Patwardhan. 2008. The role of moral intensity and moral philosophy in ethical decision making: a cross-cultural comparison of China and the European Union. Business Ethics 17, no. 2 (April 1): 196-209.

[68] Wasieleski, D and S Hayibor. 2008. Breaking the Rules: Examining the Facilitation Effects of Moral Intensity Characteristics on the Recognition of Rule Violations. Journal of Business Ethics 78, no. 1-2 275-289. 